\title{
Linking Keystone Species and Functional Groups: A New Operational Definition of the Keystone Species Concept
}

\author{
$\underline{\text { Robert D. Davic }}$
}

\begin{abstract}
The concept of the "keystone species" is redefined to allow for the a priori prediction of these species within ecosystems. A keystone species is held to be a strongly interacting species whose top-down effect on species diversity and competition is large relative to its biomass dominance within a functional group. This operational definition links the community importance of keystone species to a specific ecosystem process, e.g., the regulation of species diversity, within functional groups at lower trophic levels that are structured by competition for a limited resource. The a priori prediction of keystone species has applied value for the conservation of natural areas.
\end{abstract}

\section{INTRODUCTION}

Recent volumes of Conservation Ecology have featured debates on the definition of "keystone species" (De Leo and Levin 1997, Khanina 1998, Piraino and Fanelli 1999, Vanclay 1999, Davic 2000, 2002, Higdon 2002). This dialog adds to a decade-long controversy over the use of the keystone species concept in ecology (Lamont 1992, Bond 1993, Mills et al. 1993, Schulze and Mooney 1993, deMaynadier and Hunter 1994, Menge et al. 1994, Paine 1995, Walker 1995, Allison et al. 1996, Martinez 1996, Power et al. 1996, Hurlbert 1997, Kotliar 2000, Piraino et al. 2002). In this communication, I briefly review this controversy and propose a new operational definition that allows for the a priori prediction of keystone species within functional groups using field data collected during routine surveys of flora and fauna.

\section{THE KEYSTONE SPECIES CONTROVERSY}

The ecological term "keystone species" was coined by Paine (1969a), and subsequently defined (Paine 1969b:950) as a species of high trophic status whose activities exert a disproportionate influence on the pattern of species diversity in a community. The mechanism by which keystone species (KS) regulate species diversity was described by Paine (1966:65) in the following hypothesis: " ... local species diversity is directly related to the efficiency with which predators prevent the monopolization of the major environmental requisites by one species." Paine's (1966) experimental confirmation, in which the removal of the carnivorous seastar (Pisaster ochraceus) from intertidal habitat reduced prey species diversity due to intense competition from mussel prey, is now a textbook classic.

The original KS concept of Paine $(1969 a, 1969 b)$ thus identified a very specific ecosystem process: top-down regulation of species diversity, competitive interactions, and community persistence. The metaphor that KS are similar to the keystone of an arch is valid, because both species and stone derive their functional importance to the system as a whole from bidirectional interactions with lower energy levels. Species that play this KS role in ecosystems may be trophic generalists or specialists, rare or common, and they do not need to be important movers of energy (Paine 1969a, Bond 1993). Both short-term (Paine 1992, Raffaelli and Hall 1992) and long-term (Ernest and Brown 2001) field experiments indicate that the effect of KS on species diversity is nonredundant in ecosystems, which contributes to their great ecological significance (Bond 1993, 2001, Schulze and Mooney 1993).

However, a divergent line of thought has emerged in the ecological literature that puts aside the narrow food-web focus of Paine. According to this alternate view, a KS may be any species that has a large effect on any aspect of ecosystem function (see Lamont 
1992, Bond 1993, Mills et al. 1993, Folke et al. 1996, Higdon 2002, Piraino et al. 2002). As a result, many species have been afforded KS status because they are so-called keystone prey, competitors, mutualists, dispersers, pollinators, earth-movers, habitat modifiers, engineers, hosts, processors, plant resources, dominant trees, etc. An elaborate classification of this extensive KS typology, based on the strength of interaction effect, was presented by Lamont (1992); this is the concept of first-, second-, and third-order KS, with those of the highest order having the greatest impact on ecosystem function. This state of affairs led Mills et al. (1993) to suggest that ecologists abandon the KS concept completely because its application had become too broad, it lacked a priori operational definition, and it consequently had little applied value for the conservation of natural areas.

In response to Mills et al. (1993), a group of ecologists known as the "Keystone Cops" (Paine 1995, Power and Mills 1995) proposed the first operational definition of a KS. Hayek (1994) summarized the importance of operational definitions in the formulation of ecological concepts. An operational definition must be precise and reproducible, because it connects concepts to experimental and quantitative procedures (Hayek 1994). The operational definition proposed by the Keystone Cops is based on the proportional biomass of species in ecosystems in relation to their community importance. According to the Keystone Cops, a keystone species is a species whose effect on ecosystems is disproportionately large relative to its low biomass in the community as a whole (Power et al. 1996). In other words, KS are rare, and the a priori identification of KS in ecosystems is unlikely (Power et al. 1996). This operational definition adopted the paradigm that KS can affect a multitude of ecosystem processes and abandoned the narrow food-web focus of Paine, a view that I and others do not share (Davic 2000, 2002, Piraino et al. 2002).

Subsequent reviews by Martinez (1996), Hulbert (1997), Kotliar (2000), Bond (2001), and Piraino et al. (2002) suggest that the KS definition proposed by the Keystone Cops (Power et al. 1996) has limited applied value for conservation ecology. First, other important species known as "dominant species" may coexist with KS in ecosystems (Power et al. 1996). These dominant species can have the same total impact on ecosystem function as does the KS (Fig. 3 of Power et al. 1996). This false dichotomy between $\mathrm{KS}$ and dominant species results in an unworkable model for mangers of natural resources who need to assign priorities to ecologically significant species in their stewardship (Hulbert 1997, Kotliar 2000). Whether or not a species is considered to be keystone or dominant is a moot point if both types have identical effects on ecosystem function.

Other problems arise. To distinguish between the presence of a KS and of a dominant species, Power et al. (1996) introduce the "community importance" (CI) index,

$$
C I=[d(\text { trait }) / d p][1 / \text { trait }],
$$

where $d$ represents change over time, $p$ is the proportional biomass of the presumptive KS relative to the total biomass of all other species in the community, and trait is some quantitative aspect of a community or ecosystem, such as productivity or species richness. However, it would not be practical for an applied research program to try to quantify the total biomass of all the other species in a community. It is also not clear what exactly is meant by "community" as applied to the CI index, that is, are we to measure all plant, bacteria, fungi, and animal biomass in a given area to determine disproportionate abundance, or only the biomass of species that interact with the KS? Kotliar (2000) discusses further problems concerning "scale" in any attempt to use the CI index in an applied manner. The implicit assumption of the $\mathrm{CI}$ index, that KS effects are a linear function of their abundance in relation to the ecosystem as a whole, has been shown to be invalid (Kotliar 2000). Kotliar proposed that the CI concept should be refined to emphasize the fact that $\mathrm{KS}$ perform roles in ecosystems that are not performed by other species or processes, in agreement with the narrow food-web focus initially presented by Paine (1966, 1969a , 1969b). Piraino et al. (2002) raise concerns that the CI index applies only if a potential $\mathrm{KS}$ is removed completely during field experiments, which is a difficult proposition for most in situ experiments, and that the CI performs best where experimental communities are near equilibrium. This negates the use of the $\mathrm{CI}$ in the many nonequilibrium ecosystems that exist in nature, which is problematic given theoretical arguments that the KS may regulate species diversity in nonequilibrium communities (Caswell 1978, Connell 1978).

Finally, managers of natural resources are left with the vague task of deciding how disproportionately rare a 
potential KS may be before they decide to conduct an experiment to remove it (Martinez 1996, Bond 2001). Power et al. (1996) propose that a search for KS must begin with removing such a species from an ecosystem, with subsequent monitoring of the response of a selected ecosystem trait or traits over time. However, those species to be identified and removed a priori must, by definition, have a low biomass in relation to the community as a whole, thus forcing the researcher to search for potential KS within the veiled reality of the miniscule among the tremendous biodiversity of nature.

\section{DEFINING KEYSTONE SPECIES WITHIN FUNCTIONAL GROUPS}

\section{Keystone species redefined}

If the keystone species (KS) concept is to have applied value as recently urged (Martinez 1996, Kotliar 2000, Bond 2001, Jordán 2001, Piraino et al. 2002), yet maintain the predictive power of the narrow food-web focus of Paine, then it would be useful if there existed an a priori protocol that allowed for the identification of any species across the landscape, rare or common in relation to the community as a whole, to be targeted for potential KS status.

Here I present one such approach that defines KS within the context of functional groups: a keystone species is a strongly interacting species whose topdown effect on species diversity and competition is large relative to its biomass dominance within a functional group.

This new operational definition of a KS has a number of applied characteristics. First, it retains the original food-web focus of Paine (1966, 1969a, 1969b, 1971, 1974), namely, that a KS alleviates competitive interactions within the functional groups of its prey. Thus, it links the identity of a KS to a specific ecosystem process that can be quantified and experimentally falsified, which was suggested by Martinez $(1995,1996)$ as an important consideration in any attempt to measure the functional significance of biodiversity in ecosystems. It also conforms with Paine's (1988:1652) suggestion that, for food-web theory to become predictive, it must incorporate competitive interactions in predator-prey models. Second, the false dichotomy between so-called KS and dominant species in the definition of Power et al. (1996) is eliminated. Any species that is dominant in terms of biomass within an occupied functional group would represent a potential KS that could regulate species diversity in functional groups from lower trophic levels. This viewpoint agrees with the suggestion of Schulze (1995) that control of ecosystem processes may be shared by a variety of KS that act at multiple trophic levels within grazer and detritus food chains. Furthermore, species that are dominant within both a functional group and the ecosystem as a whole would be accorded proper recognition as potential KS, a situation not possible with the definition of Power et al. (1996). Finally, the biomass of a potential KS is calculated within the nested boundaries of its occupied functional group, not in relation to the biotic community as a whole. Thus, a step-by-step research program could be initiated to search for potential KS within distinct functional groups as time and resources allow.

This is not the first attempt to associate KS with dominance in functional groups. KS effects between dominant vertebrate predators, salamanders, and an invertebrate shredder functional group were documented in a lotic ecosystem (Davic 1983). Walker (1992, 1995) concluded that conservation efforts should be targeted toward strongly interacting species that are the sole representatives of functional groups, which he called "keystone species." Grimm (1995) also viewed $\mathrm{KS}$ as the sole members of functional groups, whereas Folke et al. (1996) and Bengtsson (1998) implied that KS could be embedded within functional groups containing multiple species. Allison et al. (1996) concluded that KS may be dominant within multispecies functional groups, but they did not link this dominance to the regulation of competitive interactions and species diversity. A computer model by Solé and Montoya (2001) predicts that functionally dominant $\mathrm{KS}$ at multiple trophic levels may regulate sets of related species, i.e., functional groups.

The above observations suggest a hypothesis that species rank-abundance patterns can predict a priori the identity of KS within a functional group in which a single or a few species are biomass-dominant. Ecologists have long searched for patterns that relate structure to function (see reviews by Tokeshi 1993, 1999). A variety of rank-abundance compositions have been offered that identify strongly interacting species in ecosystems (Mills et al. 1993, Hall and Raffaelli 1993, Estes 1995, Allison et al. 1996), which I synthesize in Fig. 1. The hollow, left-skewed distributions in Fig. 1 suggest that the a priori prediction of KS within a functional group may follow a power-law mathematical function (Bak 1996). As 
reviewed by Bak, the power law is a well-documented characteristic of aggregated self-organized systems, where $\left[f(r) \sim r^{-a}\right]$. Power-law functions are commonly used by biologists to express relationships involving physiology, ecology, and life-history characters (Marquet 2002), and they are ubiquitous within ecosystems (see review by Gaston and Blackburn 2000), so it is not unreasonable that they hold clues to the identity of strongly interacting species.

Fig. 1. Hypothetical keystone species patterns within three functional groups. Biomass-dominant taxa within each functional group represent potential keystone species. The $\mathrm{x}$-axis and $\mathrm{y}$-axis are scaled for illustrative purposes only. The two potential keystone species in the third functional group correspond to the "foundation species" concept of Dayton (1975).

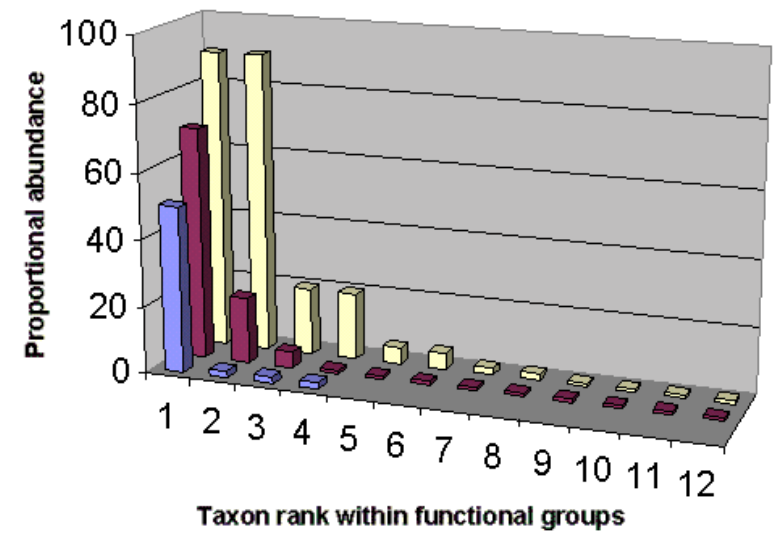

Although ecologists doubt that KS can be identified a priori without experimental observation (Paine 1966, 1995, Dayton 1975, Menge et al. 1994, Allison et al. 1996, Power et al. 1996), a growing number of a priori approaches have been suggested. Bond (1993) linked the a priori identity of $\mathrm{KS}$ to the regulation of competitive interactions among prey during ecological succession. Bond (1993) concluded that the a priori presence/absence of KS could be inferred from species rank-abundance patterns within prey guilds in which competition is known to exist. Piraino et al. (2002) also noted that KS effects might be observed a priori where long-lived prey species are equally abundant within functional groups. Recently, it has been suggested that KS can be identified a priori based on strength of interaction links in model food webs (Jordán et al. 1999, Jordán 2001, Solé and Montoya 2001).
The simple graphic approach (Fig. 1) fitted to a powerlaw function can identify obvious situations in which potential KS could be predicted within a functional group. Statistical hypothesis tests may add little to the interpretation of the rank-abundance graphs in Fig. 1 (see Johnson 1999). However, a variety of community indices could be applied to quantify the strength of $\mathrm{KS}$ dominance within a functional group. For example, the dominance index (DI) of Berger and Parker (1970) could be used to quantify KS dominance as follows:

$$
D I=N_{\max } / N,
$$

where $N_{\max }$ represents the number of individuals of the most abundant species, and $N$ is the total number of individuals within the functional group as a whole. Where more than one potential KS is identified within a functional group (see Fig. 1), the community dominance index (CDI) of McNaughton (1968) can be applied:

$$
C D I=100 *\left(y_{1}+y_{2}\right) / y,
$$

such that $y_{1}$ and $y_{2}$ represent the frequency of the two most abundant species within a functional group, and $y$ represents the total number of individuals.

I emphasize that the above approach can predict only the potential existence of a KS within an ecosystem. As discussed by Hall and Raffaelli (1993), other strongly interacting species, such as "key species" that regulate energy flow/nutrient dynamics or "ecosystem engineers" that modulate habitat structure (see Crooks 2002), may also be biomass-dominant within a functional group. Some focal species may play multiple process roles in ecosystems (Zacharias and Roff 2001). However, given the current state of affairs in ecology, i.e., the fact that all strongly interacting species in ecosystems are viewed as "keystone process species" (see Folke et al. 1996), and the suggestion that KS can be identified only after their experimental removal from food webs (Power et al. 1996), I propose an alternative paradigm: any species identified a priori as biomass-dominant within its occupied functional group should be recognized as a potential KS in the narrow conception of Paine (1969a, 1969b), until such time as that hypothesis can be proven false via controlled experimentation. As discussed below, a variety of studies now suggest that dominant species within functional groups regulate species diversity in lower trophic levels. This is, I believe, a reasonable solution to the current "keystone species controversy," because it allows for the a priori prediction of $\mathrm{KS}$, an 
important concern given the loss of global biodiversity (Wilson 1999).

Information on KS could potentially have significant applied value for managers of natural resources. Many government agencies conduct surveys of flora and fauna in which species abundance data could be aggregated into functional groups. Large datasets could be re-evaluated within a functional-group context to look for structural patterns based on species rank-abundance distributions (Fig. 1). Those species with biomass dominance within a distinct functional group could be flagged for future experimental removal to determine if they regulate species diversity in lower trophic levels, i.e., are "keystone species," and, if native species, protected until experimental effects on ecosystem processes are determined. Dominant exotic species should be viewed as potential KS that require control or removal, not protection. A narrowly defined approach to the prediction of $\mathrm{KS}$ in ecosystems could also assist efforts to provide them legal protection, such as the tabled Keystone Species Conservation Act of 1999, which failed to provide an appropriate operational definition of how KS differ from rare or endangered species (see http://www.aza.org/GovAffairs/TestimonyGreatApe/).

Ultimate determination of KS status requires that the dominant species within a functional group be removed from or added to an ecosystem to investigate its effects on species diversity within functional groups at lower trophic levels. The experimental approaches of Paine (1974, 1992), Raffaelli and Hall (1992), Menge et al. (1994), Navarrete and Menge (1996), Navarrete et al. (2000), and Ernest and Brown (2001) provide guidance. In situations in which more than one potential KS is identified a priori by their biomass dominance, each dominant species should be manipulated in a stepwise manner to determine whether or not diffuse interaction effects are present (see Menge et al. 1994, Navarrete and Menge 1996). Experimental manipulation of potential KS also could have effects on the community level, which could be measured using the index of biotic integrity (IBI) concept of Karr (1981) and Karr et al. (1986).

\section{Assembly rules for functional groups}

Clearly, the KS definition I propose in this paper will depend on the ability of ecologists to provide biologically meaningful aggregations of taxonomic species into functional groups for the ecosystems under study. This will not be an easy task, because, as discussed by Bengtsson (1998), there are no standardized sets of functional groups that are recognized for the numerous ecosystems that exist in nature. Currently, functional groups are defined in an ad hoc way based on morphological, physiological, behavioral, biochemical, or environmental responses or on trophic criteria. However, concepts of functional groups are widespread in ecology (see reviews of Walker 1992, 1995, Fox and Brown 1993, Bengtsson 1998, Harris 1999, Kinzig et al. 2001). Gitay and Noble (1997) reviewed the history of functional groups/types, and Simberloff and Dayan (1991) reviewed the guild concept and its relationship to functional groups. Numerous food-web models are now available that use functional groups to distinguish species with strong interactions (Steneck and Dethier 1994, Bengtsson 1998, de Ruiter et al. 1998, Padilla and Allen 2000).

One route toward the discovery of functional groups that may harbor potential KS is to identify clusters of species with similar evolutionary histories (Chapin et al. 1992) that can be further aggregated into feeding guilds by trophic level (Cohen and Briand 1984) and foraging behavior. This viewpoint was advocated by Martinez (1996) and by Martinez and Dunne (1998) as a way to aggregate the complex functional diversity of ecosystems, and adopted by Fox and Brown (1993) in their study of a Nevada desert ecosystem. Fox and Brown (1993) aggregated 14 species of rodents (Order Rodentia) into three feeding guilds, namely, granivores, folivores, and insectivores, which were further divided into five "functional groups" based on clearly defined foraging strategies. They suggested that this type of functional group representation is more predictive of ecosystem processes than exclusively taxonomic or morphological approaches. Fox and Brown (1993) concluded that the mechanism underlying this assembly rule for functional groups is interspecific competition, which is congruent with the concept of Paine $(1969 a, 1969 b)$ that KS serve to alleviate competitive interactions within functional groups of their prey.

Here I adopt the functional group definition outlined by Fox and Brown (1993:360) for the a priori prediction of potential KS in ecosystems, and offer the following as a way of clustering species into functional groups to search for KS. First, aggregate species into evolutionary taxa at the taxonomic level of either the family or order; Fox and Brown (1993) used the order to define functional groups for a desert ecosystem, whereas Bellwood and Hughes (2001) 
suggested that the family could serve to predict functional groups in a coral reef habitat. Next, further aggregate the species within each evolutionary taxon into feeding guilds by trophic level along grazer or detritus food chains; this approach was advocated by Martinez and Dunne (1998). Finally, within each feeding guild, aggregate species into functional groups based on distinct foraging strategies as suggested by Fox and Brown (1993). Using this approach, the presence of a potential KS would be identified by its biomass dominance within each identified functional group (see Fig. 1). A search for KS within functional groups would also need to consider the changes in life history that occur during ontogeny (Power 1995, review by Polis and Winemiller 1996) and ecological succession (Walker et al. 1999). Species with complex life cycles (Wilbur 1997) may occupy more than one functional group at different life-history stages.

Table 1. Hypothetical food web of 16 species aggregated by trophic-based functional groups. Two potential keystone species are identified a priori by their biomass dominance within the top carnivore and herbivore functional groups.

\begin{tabular}{lcccc}
\hline \multirow{2}{*}{ Functional group } & \multicolumn{4}{c}{ Biomass $\left(\mathrm{g} / \mathrm{m}^{2}\right)$} \\
\cline { 2 - 5 } & Species A & Species B & Species C & Species D \\
\hline Top carnivore & 0.20 & $\ldots$ & $\ldots$ & $\ldots$ \\
Tertiary consumer & 0.60 & 0.50 & 0.40 & $\ldots$ \\
Secondary consumer & 5.20 & 4.90 & 0.90 & 3 \\
Herbivore & 109 & 13 & 7 & 147 \\
Primary producer & 200 & 185 & 171 & 140 \\
\hline
\end{tabular}

\section{Hypothetical example}

Odum (1971:80) presents biomass data in $\mathrm{g} / \mathrm{m}^{2}$ for a marine ecosystem, the Eniwetok Coral Reef, that I have modified (Table 1) by adding two consumer trophic links and hypothetical species to illustrate how potential KS can be identified a priori within functional groups from biomass data collected during routine surveys of flora and fauna.

Assume that functional groups have been identified as outlined above. Consider a herbivore assemblage with four species that feed exclusively on an assemblage of primary producers, an assemblage of secondary consumers that feed exclusively on herbivores, a tertiary consumer assemblage that feeds jointly on the secondary consumers and herbivores, and a single top carnivore that feeds on the three consumer functional groups, but is not itself prey for other consumers (see Table 1). This food web contains no omnivore functional group, defined following Wilson and Bossert (1971) as animals that feed on both animals and plants, although the top carnivore and tertiary consumer functional groups represent interguild consumers, defined here as consumers that feed on other consumers at multiple trophic levels. Assume that a manager of this ecosystem has been asked to determine if any potential KS are present for future experimental investigation.

I suggest it is possible to predict a prior the identity of the potential KS that exist in the community of 16 species presented in Table 1. Analysis of the biomass data indicates that potential $\mathrm{KS}$, both in the column labeled "Species A," can be identified within the tertiary consumer and herbivore functional groups because they have proportional biomass values that are significantly dominant within their functional groups [See erratum]. Note that one of these potential KS, the top carnivore, has proportionally low biomass in relation to the community as a whole, i.e., it is biomass-rare, whereas the KS herbivore has the highest proportional biomass of all 12 consumers, i.e, it is the biomass-dominant consumer. This example 
illustrates the false dichotomy that can arise between so-called KS and dominant species in the current definition of Power et al. (1996).

Using the data from Table 1, the manager can now formulate an a priori hypothesis that the experimental removal of the dominant top carnivore and/or herbivore would result in large effects on species diversity within the functional groups of lower trophic levels. Note that KS are not predicted to be present within the tertiary consumer and primary producer functional groups because no species are biomassdominant, although the secondary consumer functional group may show compensatory KS effects by the two codominant consumers, i.e., the "foundation species" concept of Dayton (1975).

\section{SUMMARY}

In this communication, I offer a new operational definition of the keystone species concept that allows for the a priori prediction of keystone species within functional groups aggregated by evolutionary history, feeding guilds, and foraging patterns following the functional group assembly rules of Fox and Brown (1993). I believe that this approach is timely because debate is now shifting to recognize that ecosystem processes are more likely to be related to the distribution of species within and between functional groups than to traditional taxonomic representations of species diversity in a community (Chapin et al. 1997, Bengtsson 1998, Walker 1992, 1995, Harris 1999, Walker et al. 1999). Given the increased rate of global loss of biodiversity (Wilson 1999) and calls for their legal protection, e.g., the proposed Keystone Species Conservation Act of 1999, managers of natural resources can no longer wait for the results of detailed field experiments involving the removal of keystone species or for models of the strengths of complex food-web interactions to determine if potential keystone species are or are not present in the ecosystems under their stewardship. Clearly, the science of ecology must move the keystone species debate toward the formulation of operational definitions that allow for their a priori identification in ecosystems, if for no other reason than to allow for their protection before they are extirpated.

Defining a potential keystone species as biomassdominant within a functional group has appeal because this definition conforms to the original keystone species perception of Paine $(1966,1969 a)$. Recall that Paine $(1969 a)$ identified the seastar, Pisaster ochraceus, as the first example of his original keystone species concept. Of interest is the fact, not widely cited, that Pisaster was also identified as "abundant" and the "dominant carnivore" in the habitat from which it was experimentally removed (Paine 1969a:92). This abundance-dominance by Pisaster occurred within a representation of the experimental subweb that contained three trophic levels (Fig. 1 in Paine 1966), and was further discussed in Fig. 32 of MacArthur and Wilson (1967). Thus, the flagship keystone species in ecology, $P$. ochraceus, was immediately recognized by these ecologists as being biomass-dominant within a clearly defined topcarnivore functional group, and thus provides compelling, if not conclusive, support for the keystone species definition that I propose. Because it was the sole member of its top-carnivore functional group, Pisaster likewise conforms to the concept of the single strong-interacting keystone species put forth by Walker $(1992,1995)$.

Dayton (1975) concluded that the ecosystem importance of keystone species has no relation to their rank abundance or biomass because they are "rare and/or small." Although this view of nature may hold within the context of the ecosystem as a whole, as discussed above, it is incorrect when viewed from the perspective of functional groups. Many documented keystone species, including the classic Pisaster seastar of Paine (1966), sea otter (Estes 1995), fish in mangroves (Twilley et al. 1996), salamanders in forests (Wyman 1998), and coyote in deserts (Henke and Bryant 1999) are biomass-dominant within distinct functional groups and are often the sole member with strongly interacting effects (Walker 1992, 1996).

The keystone species definition that I suggest distinguishes the community importance of keystone species from other strongly interacting species in ecosystems, i.e., "keystone species" regulate local species diversity in lower trophic levels, "key species" regulate energy/nutrient dynamics, "intraguild competitors/predators" structure niche partitioning among closely related species, and "ecosystem engineers" modulate physical habitat. Some focal species (Zacharias and Roff 2001) may have multiple process roles in ecosystems. I believe that applied ecology benefits when the multiple process roles of species are discussed separately.

Responses to this article can be read online at: http://www.consecol.org/vol7/issl/resp1 1/responses/index.html 
ERRATUM (1). In the original published version of this manuscript, there was an error in the sentence: Analysis of the biomass data indicates that potential KS, both in the column labeled "Species A," can be identified within the tertiary consumer and herbivore functional groups because they have proportional biomass values that are significantly dominant within their functional groups.

The corrected sentence appears in full below.

Analysis of the biomass data indicates that potential $\mathrm{KS}$, both in the column labeled "Species A," can be identified within the top carnivore and herbivore functional groups because they have proportional biomass values that are significantly dominant within their functional groups.

\section{Acknowledgments:}

The comments of three anonymous reviewers helped to clarify this presentation.

\section{LITERATURE CITED}

Allison, G. W., B. A. Menge, J. Lubchenco, and S. A. Navarrete. 1996. Predictability and uncertainty in community regulation: consequences of reduced consumer diversity in coastal rocky ecosystems. Pages 371-392 in $\mathrm{H}$. A. Mooney, J. H. Cushman, E. Medina, O. E. Sala and E.-D. Schulze, editors. Functional roles of biodiversity: a global perspective. John Wiley, Chichester, UK.

Bak, P. 1996. How nature works: the science of selforganized criticality. Springer-Verlag, New York, New York, USA.

Bellwood, D. R., and T. P. Hughes. 2001. Regional-scale assembly rules and biodiversity of coral reefs. Science 292:1532-1534.

Bengtsson, J. 1998. Which species? What kind of diversity? Which ecosystem function? Some problems in studies of relations between biodiversity and ecosystem function. Applied Soil Ecology 10:191-199.

Berger, W. H., and F. L. Parker. 1970. Diversity of planktonic Foraminifera in deep sea sediments. Science 168: $1345-1347$.
Bond, W. J. 1993. Keystone species. Pages 237-253 in E.D. Schulze and H. A. Mooney, editors. Biodiversity and ecosystem function. Springer-Verlag, Berlin, Germany.

Bond, W. 2001. Keystone species: hunting the snark? Science 292:63-64.

Caswell, H. 1978. Predator-mediated coexistence: a nonequilibrium model. American Naturalist 112:127-154.

Chapin, F. S., III, E.-D. Schulze, and H. A. Mooney. 1992. Biodiversity and ecosystem processes. Trends in Ecology and Evolution 7:107-108.

Chapin, F. S., III, R. H. Walker, R. J. Hobbs, D. U. Hooper, J. H. Lawton, O. E. Sala, and D. Tilman. 1997. Biotic control over functioning of ecosystems. Science 277:500-504.

Cohen, J. E., and F. Briand. 1984. Trophic links of community food webs. Proceedings of the National Academy of Sciences 81:4105-4109

Connell, J. H. 1978. Diversity in tropical rainforests and coral reefs. Science 199:1302-1310.

Crooks, J. A. 2002. Characterizing ecosystem-level consequences of biological invasions: the role of ecosystem engineers. Oikos 97:153-166.

Davic, R. D. 1983. An investigation of salamander guild predation in a North Carolina stream: an experimental approach. Dissertation, Kent State University, Kent, Ohio, USA.

Davic, R. D. 2000. Ecological dominants vs. keystone species: a call for reason. Conservation Ecology 4(1):r2. [online] URL: http://www.consecol.org/vol4/iss1/resp2.

Davic, R. D. 2002. Herbivores as keystone predators. Conservation Ecology 6(2):r8. [online] URL: http;//www.consecol.org/vol6/iss2/resp8.

Dayton, P. K. 1975. Experimental evaluation of ecological dominance in a rocky intertidal algal community. Ecological Monographs 45:137-159.

De Leo, G. A., and S. Levin. 1997. The multifaceted aspects of ecosystem integrity. Conservation Ecology 1(1):3 [online] URL: http://www.consecol.org/vol1/iss1/art3.

deMaynadier, P., and M. L. Hunter. 1994. Keystone support. Bioscience 44:2.

de Ruiter, P. C., A.-M. Neutel, and J. C. Moore. 1998. Biodiversity in soil ecosystems: the role of energy flow and community stability. Applied Soil Ecology 10:217-228.

Ernest, S. K., and J. H. Brown. 2001. Delayed compensation for missing keystone species by colonization. Science 292:101-104. 
Estes, J. A. 1995. Top-level carnivores and ecosystem effects: questions and approaches. Pages 151-158 in C. G. Jones and J. H. Lawton, editors. Linking species and ecosystems. Chapman and Hall, New York, New York, USA.

Folke, C., C. S. Holling, and C. Perrings. 1996. Biological diversity, ecosystems, and the human scale. Ecological Applications 6:1018-1024.

Fox, B. J., and J. Brown. 1993. Assembly rules for functional groups in North American desert rodent communities. Oikos 67:358-370.

Gaston, K. J., and T. M. Blackburn. 2000. Pattern and process in macroecology. Blackwell Science, Oxford, UK.

Gitay, H., and I. R. Noble. 1997. What are functional types and how should we seek them? Pages 3-19 in T. M. Smith, H. H. Shugart, and F. I. Woodward, editors. Plant functional types: their relevance to ecosystem properties and global change. Cambridge University Press, Cambridge, UK.

Grimm, N. B. 1995. Why link species and ecosystems? A perspective from ecosystem ecology. Pages 6-15 in C. G. Jones and J. H. Lawton, editors. Linking species and ecosystems. Chapman and Hall, New York, New York, USA.

Hall, S. J., and D. G. Raffaelli. 1993. Food webs: theory and reality. Pages 187-239 in M. Begon and A. H. Fitter, editors. Advances in ecological research. Volume 24. Academic Press, London, UK.

Harris G. 1999. This is not the end of limnology (or of science): the world may well be a lot simpler than we think. Freshwater Biology 42:689-706.

Hayek, L.-A. C. 1994. Research design for quantitative amphibian studies. Pages 21-40 in W. R. Heyer, M. A. Donnelly, R. W. McDiarmid, L.-A. C. Hayek, and M. S. Foster, editors. Measuring and monitoring biological diversity: standard methods for amphibians. Smithsonian Institution Press, Washington, D.C., USA.

Henke, S. E., and F. C. Bryant. 1999. Effects of coyote removal on the faunal community in western Texas. Journal of Wildlife Management 63:1066-1081.

Higdon, J. W. 2002. Functionally dominant herbivores as keystone species. Conservation Ecology 6(2):r4. [online] URL: http://www.consecol.org/Journal/vol6/iss2/resp4.

Hurlbert, S. H. 1997. Functional importance vs. keystoneness: reformulating some questions in theoretical biocenology. Australian Journal of Ecology 22:369-382.

Johnson D. H. 1999. The insignificance of statistical significance testing. Journal of Wildlife Management 63:763-772.

Jordán, F. 2001. Trophic fields. Community Ecology
2:181-185.

Jordán, F., A. Takács-Sánta, and I. Molnár. 1999. A reliability theoretical quest for keystones. Oikos 86:453-462.

Karr, J. R. 1981. Assessment of biotic integrity using fish communities. Fisheries 6:21-27.

Karr, J. R., K. D. Fausch, P. L. Angermeier, P. R. Yant, and I. J. Sclosser. 1986. Assessing biological integrity in running waters: a method and its rationale. Special Publication Number 5. Illinois Natural History Survey, Champaign, Illinois, USA.

Khanina, L. 1998. Determining keystone species. Conservation Ecology 2(2):r2. [online] URL: http://www.consecol.org/Journal/vol2/iss2/resp2.

Kinzig, A. P., S. W. Pacala, and D. Tilman. 2001. The functional consequences of biodiversity: empirical progress and theoretical extensions. Princeton University Press, Princeton, New Jersey, USA.

Kotliar, N. B. 2000. Application of the new keystonespecies concept to prairie dogs: how well does it work? Conservation Biology 14:1715-1721.

Lamont, B. B. 1992. Functional interactions within plants-the contribution of keystone and other species to biological diversity. Pages 95-127 in R. J. Hobbs, editor. Biodiversity in Mediterranean ecosystems of Australia. Surrey Beatty, Chipping Norton, Australia.

MacArthur, R. H., and E. O. Wilson. 1967. The theory of island biogeography. Princeton University Press, Princeton, New Jersey, USA.

Marquet, P. A. 2002. Of predators, prey, and power laws. Science 295:2229-2230.

Martinez, N. D. 1995. Unifying ecological subdisciplines with ecosystem food webs. Pages 166-175 in C. G. Jones and J. H. Lawton, editors. Linking species and ecosystems. Chapman and Hall, New York, USA.

Martinez, N. D. 1996. Defining and measuring functional aspects of diversity. Pages 114-148 in K. J. Gaston, editor. Biodiversity: a biology of numbers and difference. Blackwell Science, Cambridge, UK.

Martinez, N. D., and J. A. Dunne. 1998. Time, space, and beyond: scale issues in food-web research. Pages 207-226 in D. L. Peterson and V. T. Parker, editors. Ecological scale: theory and applications. Columbia University Press, New York, New York, USA.

McNaughton. S. J. 1968. Structure and function in California grasslands. Ecology 49:962-972.

Menge, B. A., E. L. Berlow, C. A. Blanchette, S. A. Navarrete, and S. B. Yamada. 1994. The keystone species concept: variation in interaction strength in a rocky 
intertidal habitat. Ecological Monographs 64:249-286.

Mills, L. S., M. E. Soulé, and D. F. Doak. 1993. The keystone-species concept in ecology and conservation. Bioscience 43:219-224.

Navarrete, S. A., and B. A. Menge. 1996. Keystone predation and interaction strength: interactive effects of predators on their main prey. Ecological Monographs 66:409-429.

Navarrete, S. A., B. A. Menge, and B. A. Daley. 2000. Species interactions in intertidal food webs: prey or predation regulation of intermediate predators? Ecology 81:2264-2277.

Odum, E. P. 1971. Fundamentals of ecology. Third edition. W. B. Saunders, Philadelphia, Pennsylvania, USA.

Padilla, D. K., and B. J. Allen. 2000. Paradigm lost: reconsidering functional form and group hypotheses in marine ecology. Journal of Experimental Marine Biology and Ecology 250:207-221.

Paine, R. T. 1966. Food web complexity and species diversity. American Naturalist 100:65-75.

Paine, R. T. 1969a. A note on trophic complexity and community stability. American Naturalist 103:91-93.

Paine, R. T. 1969b. The Pisaster-Tegula interaction: prey patches, predator food preference, and intertidal community structure. Ecology 50: 950-961.

Paine, R. T. 1971. A short-term experimental investigation of resource partitioning in a New Zealand rocky intertidal habitat. Ecology 52:1096-1106.

Paine, R. T. 1974. Intertidal community structure: experimental studies on the relationship between a dominant competitor and its principal predator. Oecologia (Berlin) 15:93-120.

Paine, R. T. 1988. Food webs: road maps of interactions or grist for theoretical development? Ecology 69:1648-1654.

Paine, R. T. 1992. Food-web analysis through field measurement of per capita interaction strength. Nature 355:73-75.

Paine, R. T. 1995. A conversation on refining the concept of keystone species. Conservation Biology 9:962-964.

Piraino, S., and G. Fanelli. 1999. Keystone species: what are we talking about? Conservation Ecology 3(1):r4. [online] URL: http://www.consecol.org/vol3/iss1/resp4.

Piraino, S., G. Fanelli, and F. Boero. 2002. Variability of species' roles in marine communities: change of paradigms for conservation priorities. Marine Biology 140:1067-1074.

Polis, G. A., and K. O. Winemiller. 1996. Food webs: integration of patterns and dynamics. Chapman and Hall, New York, New York, USA.

Power, M. E. 1995. Floods, food chains, and ecosystem processes in rivers. Pages 52-60 in C. G. Jones and J. H. Lawton, editors. Linking species and ecosystems. Chapman and Hall, New York, New York, USA.

Power, M. E., and L. S. Mills. 1995. The keystone cops meet in Hilo. Trends in Ecology and Evolution 10:182-184.

Power, M. E., D. Tilman, J. A. Estes, B. A. Menge, W. J. Bond, L. S. Mills, G. Daily, J. C. Castilla, J. Lubchenco, and R. T. Paine. 1996. Challenges in the quest for keystones. Biosience 46:609-620.

Raffaelli, D., and S. J. Hall. 1992. Compartments and predation in an estuarine food web. Journal of Animal Ecology 61:551-560.

Schulze, E.-D., and H. A. Mooney. 1993. Ecosystem function of biodiversity: a summary. Pages 497-510 in E.-D. Schulze and H. A. Mooney, editors. Biodiversity and ecosystem function. Springer-Verlag, Berlin, Germany.

Schulze, E.-D. 1995. Flux control at the ecosystem level. Trends in Ecology and Evolution 10:40-43.

Simberloff, D. and T. Dayan. 1991. The guild concept and the structure of ecological communities. Annual Review of Ecology and Systematics 22:115-143.

Solé, R. V., and J. M. Montoya. 2001. Complexity and fragility in ecological networks. Proceedings of the Royal Society of London B. 268:2039-2045.

Steneck, R. S., and M. N. Dethier. 1994. A functional group approach to the structure of algal-dominated communities. Oikos 69:476-498.

Tokeshi, M. 1993. Species abundance patterns and community structure. Pages 112-186 in M. Begon and A. H. Fitter, editors. Advances in ecological research. Volume 24. Academic Press, London, UK.

Tokeshi, M. 1999. Species coexistence: ecological and evolutionary perspectives. Blackwell Science, Oxford, UK.

Twilley R. R., S. C. Snedaker, A. Yáñez-Arancibia, and E. Medina. 1996. Biodiversity and ecosystem processes in tropical estuaries: perspectives of mangrove ecosystems. Pages 327-370 in H. A. Mooney, J. H. Cushman, E. Medina, O. E. Sala, and E.-D. Schulze, editors. Functional roles of biodiversity: a global perspective. John Wiley, Chichester, UK.

Vanclay, J. 1999. On the nature of keystone species. Conservation Ecology 3(1):r3. [online] URL: http://www.consecol.org/vol3/iss1/resp3.

Walker, B. H. 1992. Biodiversity and ecological redundancy. Conservation Biology 6:18-23. 
Walker, B. H. 1995. Conserving biological diversity through ecosystem resilience. Conservation Biology 9:747:752.

Walker, B. H., A. Kinzig, and J. Langridge. 1999. Plant attribute diversity, resilience, and ecosystem function: the nature and significance of dominant and minor species. Ecosystems 2:95-113.

Wilbur, H. M. 1997. Experimental ecology of food webs: complex systems in temporary ponds. Ecology 78:22792302 .

Wilson, E. O. 1999. The diversity of life. W. W. Norton, New York, New York, USA.

Wilson, E. O., and W. H. Bossert. 1971. A primer of population biology. Sinauer, Sunderland, Massachusetts, USA.

Wyman, R. L. 1998. Experimental assessment of salamanders as predators of detrital food webs: effects on invertebrate decomposition and the carbon cycle. Biodiversity and Conservation 7:641-650.

Zacharias, M. A., and J. C. Roff. 2001. Use of focal species in marine conservation and management: a review and critique. Aquatic Conservation: Marine and Freshwater Ecosystems 11:59-76. 